\title{
ELECTRODES FOR WELDING OF DISSIMILAR CHROMIUM MARTENSITIC AND CHROMIUM-NICKEL AUSTENITIC STEELS
}

\author{
L.S. ZAKHAROV, A.R. GAVRIK and V.N. LIPODAEV \\ E.O. Paton Electric Welding Institute, NASU \\ 11 Bozhenko Str., 03680, Kiev, Ukraine. E-mail: office@paton.kiev.ua
}

\begin{abstract}
Carried are the investigations on development of low-carbon chromium electrodes of 05Kh6MF type. Effect of coating composition on carbon content in deposited metal of Kh6M type was investigated. It is determined that joint introduction of chromium and zirconium oxides in 5-10 wt.\% amount at simultaneous removal of marble from the coating is the most efficient for carbon reduction. Slag system of fluoride-magnesium oxide type coating was developed, providing reduction of carbon content in the deposited metal to 0.040.06 wt.\% at sufficiently low content of diffusible hydrogen. Electrodes of ANL-10 grade for welding of dissimilar joints of chromium martensitic steels of 10Kh9NMFB type and chromium-nickel austenitic steels of $10 \mathrm{Kh} 18 \mathrm{~N} 10 \mathrm{~T}$ type were developed on its basis. The electrodes provide for stable arcing, insignificant spattering, good weld formation in all spatial positions and easy separation of slag crust. 12 Ref., 3 Tables, 2 Figures.
\end{abstract}

$\boldsymbol{K} \boldsymbol{e} \boldsymbol{y} \boldsymbol{w} \boldsymbol{o r d} \boldsymbol{s}:$ arc welding, dissimilar steels, coated electrodes, deposited metal, carbon reduction, diffusible hydrogen, welding-technological properties

Martensitic steels of 10Kh9NMFB type are currently used in power-generating units with supercritical vapor parameters (operating temperature $600{ }^{\circ} \mathrm{C}$ ). They have higher long-term strength and larger corrosion resistance due to complex system of alloying and high-content of chromium than traditional low-alloy pearlitic and bainitic steels [1]. Such steels are included in the joints of pipe systems having operating temperature more than $610{ }^{\circ} \mathrm{C}$ and manufactured from austenitic steels of $10 \mathrm{Kh} 18 \mathrm{~N} 10 \mathrm{~T}$ type during construction of new power units and repair of old pipe systems.

It is well-known fact that filler materials, providing high-nickel austenitic deposited metal, are usually used in welding of dissimilar joints, operating at temperature above $500{ }^{\circ} \mathrm{C}$. However, our investigations showed that formation of chains of grains of structurally free ferrite is observed in HAZ of P91 steel in welding of martensitic steel 10Kh9NMFB (P91) to austenitic steel 10Kh18N10T, even at nickel content in the weld metal more than $50 \mathrm{wt} \%$ (Figure 1, $a$ ). This can promote significant reduction of serviceability of welded structures [2]. Therefore, necessity in change of technology of welding of such joints has emerged.

The investigations performed showed that prevention of formation of ferrite interlayer and pro-

Figure 1. Microstructure $(\times 300)$ of fusion zone of steel $10 \mathrm{Kh} 9 \mathrm{NMFB}$ with austenitic weld

viding of necessary strength characteristics of fusion zone require preliminary cladding of 10Kh9NMFB steel edge by special filler material (Figure $1, b$ ), containing 5-7 wt.\% $\mathrm{Cr}$ and $0.8-$ 1.0 wt.\% Mo. Content of carbon in the deposited metal should lie in $0.04-0.06$ wt.\% limits. In this case, materials of 10Kh16N25 type can be used for filling of main section of the weld. Since the

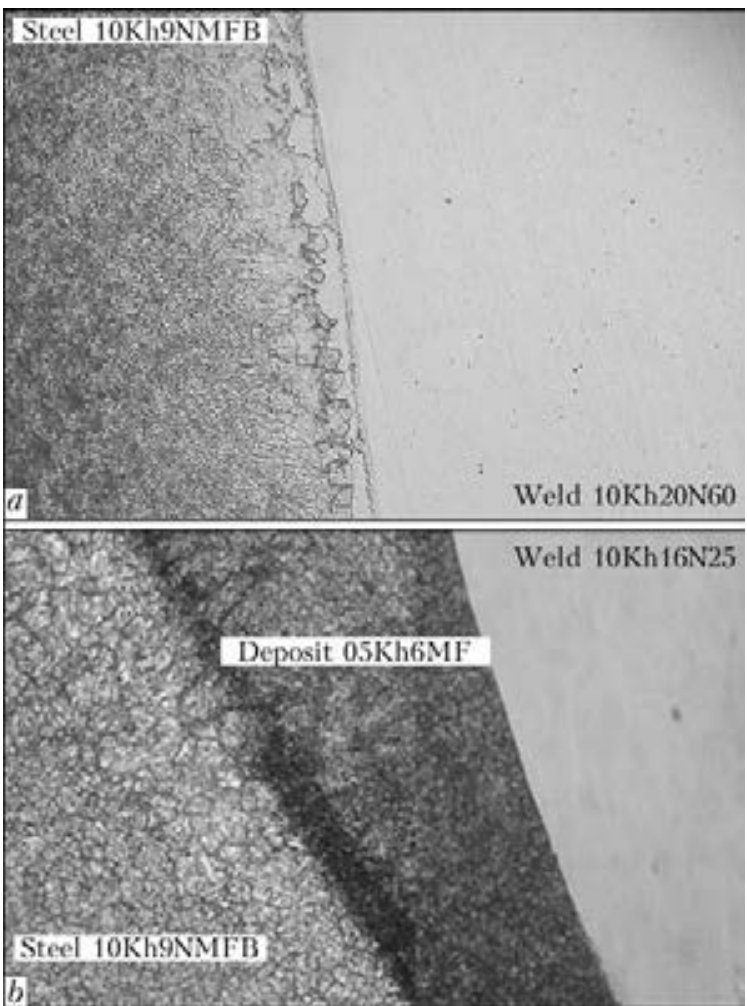


VIII INTERNATIONAL CONFERENCE «WELDING CONSUMABLES》

Table 1. Chemical composition of deposited metal, wt.\%, in use of standard electrodes with $8-12$ wt.\% Cr

\begin{tabular}{|c|c|c|c|c|c|c|c|c|}
\hline Electrode grade & $\mathrm{C}$ & $\mathrm{Si}$ & $\mathrm{Mn}$ & $\mathrm{Cr}$ & $\mathrm{Ni}$ & Mo & $\mathrm{S}$ & $\mathrm{P}$ \\
\hline TsL-32 & $0.12-0.16$ & $<0.50$ & $0.3-0.7$ & $10-12$ & $0.8-1.1$ & $0.90-1.25$ & $<0.03$ & $<0.035$ \\
\hline TsL-41 & $<0.10$ & $<0.75$ & $0.2-0.6$ & $11-14$ & $1.0-1.5$ & - & $<0.03$ & $<0.035$ \\
\hline TsL-51 & $<0.04$ & $<0.35$ & $0.15-0.60$ & $12-15$ & $1.8-2.5$ & - & $<0.025$ & $<0.030$ \\
\hline TsL-57 & $0.06-0.14$ & $<0.60$ & $0.3-0.8$ & $8.5-10.5$ & - & $0.9-1.2$ & $<0.025$ & $<0.030$ \\
\hline
\end{tabular}

electrodes providing such alloying and reduced content of carbon in the deposited metal were not used earlier, the investigations on their development were carried out.

Electrodes of two types, namely carbonatefluorite (TsL-32, TsL-41) and rutile-fluorite-carbonate (TsL-51, TsL-57), are usually used for welding of steel with $8-12$ wt.\% Cr. At that, fluorite to marble proportion changes in large ranges (from 3.5:5.0 to 5.3:3.5). Table 1 shows that only TsL-51 electrodes provide for reduced content of carbon in the deposited metal. They are produced using low-carbon wire of $\mathrm{Sv}$ 01Kh12N2-VI grade with 12-15 wt.\% $\mathrm{Cr}$ and 2-3 wt.\% Ni. Such a wire can provide for the necessary content of alloying elements, therefore, the investigations were carried out on development of low-carbon chromium electrodes of 05Kh6MF type based on wire of Sv-08A grade with alloying through coating. Since carbon content in it can achieve $0.10 \mathrm{wt} . \%$, it was necessary to select coating composition, providing its reduction to $0.04-0.06$ wt.\%.

Burning-out of carbon in welding depends on number of factors, i.e. method and mode of welding, composition and amount of shielding medium, initial content of carbon in filler material etc. [3-7].

Transfer of carbon in the deposited metal during manual welding using coated electrodes is effected by coating composition, its thickness (coating mass factor) as well as mode of welding. Welding with electrodes having quartz and hematite-based coating shows the largest burning-out of carbon and the lowest one is observed applying fluorspar [3].

Increase of carbon content in the weld metal during manual welding using electrodes with lime fluorspar coating takes place mainly due to carbon oxide, which is formed as a result of decomposition of marble as well as carbon of ferroalloys, being introduced into the coating. In this connection, quantity of marble in the coating of electrodes for welding of high-alloy low-carbon steels is reduced to the minimum or completely removed [6].
Carbon reduction from the coating takes place due to deoxidizing agents, which are included in it or in the electrode core. Thus, rise of carbon content as a result of interaction with carbon dioxide, which is formed at $\mathrm{CaCO}_{3}$ dissociation, is observed during heating of ferromanganese in mixture with marble up to $600-900{ }^{\circ} \mathrm{C}$. Rise of content of carbon in chromium from 0.08 to $0.7-$ 1.5 wt.\% [3] is noted in coatings from marble mixture with metallic chromium after specimen heating in the furnace.

It should be noted that transfer of carbon in the deposited metal depends not only on coating composition, but also on carbon content in electrode core metal. Its burning is observed in rise of marble/fluorite proportion at high content of carbon in wire (Sv-18GSA). It is explained by increase of oxidizing potential of the coating. On the contrary, its content increases in the deposited metal at low carbon content in wire $\left(\mathrm{Sv}^{-}\right.$ 06Kh19N9T) [5].

Reduction of marble content and introduction of iron oxides (hematite, magnetite or iron dross) in electrode coating can prevent increase of carbon content in the deposited metal as well as somewhat decrease it [7]. Using of more thermally resistant oxides $\mathrm{Cr}_{2} \mathrm{O}_{3}$ and $\mathrm{ZrO}_{2}$ is more efficient in welding by electrodes with rutile-lime fluorspar coating, which contains up to 10 wt.\% of marble [8]. This is explained by the fact that they have more than $2000{ }^{\circ} \mathrm{C}$ melting temperature and react with carbon at higher temperature, at which it becomes more active deoxidizing agent. Besides, carbon oxidation is possible at drop stage, since dissociation of $\mathrm{Cr}_{2} \mathrm{O}_{3}$, on data of [9], takes place at temperature below the temperature of its melting. In addition, chromium oxides are volatile at melting temperature $\left(\sim 2400{ }^{\circ} \mathrm{C}\right)[8$, $10]$ and, thus, they can be present in gaseous phase of arc gap.

According to work [7], the higher the oxide melting temperate and the lower the chemical affinity of given oxide with oxygen, characterizing by thermodynamic potential of oxide formation $\Delta Z^{0}$, the more intensive is oxidizing of carbon, manganese or chromium. Due to high chemical affinity of zirconium with oxygen in 
Table 2. Content of components in dry charge, wt.\%

\begin{tabular}{|c|c|c|c|c|c|c|c|c|c|}
\hline \multirow{2}{*}{ Charge component } & \multicolumn{9}{|c|}{ Number of variant } \\
\hline & 1 & 2 & 3 & 4 & 5 & 6 & 7 & 8 & 9 \\
\hline Marble & 53 & 10 & 10 & 0 & 0 & 0 & 0 & 0 & 0 \\
\hline Flourite & 10 & 10 & 10 & 10 & 10 & 10 & 10 & 15 & 20 \\
\hline Fired magnesite & 0 & 30 & 30 & 30 & 30 & 30 & 30 & 30 & 30 \\
\hline Chromium oxide & - & - & - & 2 & 5 & 8 & 12 & 12 & 12 \\
\hline Zirconium concentrate & - & - & - & - & - & - & - & 5 & 10 \\
\hline Ferrotitanium & 15 & 15 & 10 & 10 & 10 & 10 & 10 & 10 & 10 \\
\hline
\end{tabular}

comparison with chromium, oxide of the first provides for smaller oxidizing of the elements than oxide of the second. The oxides of iron and nickel with melting temperature below $2000{ }^{\circ} \mathrm{C}$ provide for insignificant oxidizing of carbon and sufficiently intensive oxidizing of manganese and, in particular, of silicon.

Probably, chromium oxide should get advantage in application during development of lowcarbon chromium electrodes, since, in this case, chromium reduction takes place simultaneously with electrode burning-out.

Treatment of raw materials, namely high-temperature baking of mineral slag-forming components of charge, can be additional mean for limitation of quantity of carbon in the weld metal except for effect of coating slag system. Soaking of fluorite concentrate, rutile, hematite etc. at $800{ }^{\circ} \mathrm{C}$ during $2 \mathrm{~h}$ allows reducing content of carbon in the deposited metal per 0.010.03 wt.\% [11].

Modes of welding also influence transfer of carbon in the deposited metal. Thus, increase of arc voltage (arc length) in welding using UONI$13 / 55$ electrodes promotes decrease of carbon content almost 2 times. It can be explained by rise of period of droplet existence and more overall reac- tion. At the same time, change of welding current has virtually no effect on this process [12].

Analysis of reference data allows determining the following directions of performance of the experiments on development of low-carbon highchromium electrodes, namely reduction of content or complete removal of carbonates from coating composition, additional introduction of active oxides, rise of coating mass factor, preliminary baking of charge components.

Pilot batches of electrodes were manufactured for selection of optimum coating composition. Influence of type of coating on transfer of alloying components, content of gases in the deposited metal and welding-technological properties of the electrodes were studied.

In the first series of experiments fired (metallurgical) magnesite was introduced in the coating of UONI-13/45 type electrodes instead of marble. It was experimentally stated that reduction of carbon in the deposited metal is observed only at simultaneous decrease of ferrotitanium content in the coating. Otherwise, carbon reduction can be even observed.

Chromium and zirconium oxides (Table 2, variants 4-9) were additionally introduced in the coating composition for more efficient reduction

Table 3. Chemical composition of deposited metal, wt.\%, in use of pilot electrodes

\begin{tabular}{|c|c|c|c|c|c|c||}
\hline $\begin{array}{c}\text { Number of variant } \\
\text { (acc. to Table 2) }\end{array}$ & $\mathrm{C}$ & $\mathrm{Si}$ & $\mathrm{Mn}$ & $\mathrm{Cr}$ & Mo & $\mathrm{V}$ \\
\hline 1 & 0.079 & 0.27 & 0.37 & 5.1 & 0.71 & 0.24 \\
\hline 2 & 0.091 & 0.57 & 0.53 & 5.8 & 0.77 & 0.31 \\
\hline 3 & 0.067 & 0.63 & 0.38 & 6.6 & 0.75 & 0.38 \\
\hline 4 & 0.075 & 0.37 & 0.51 & 7.2 & 0.84 & 0.35 \\
\hline 5 & 0.063 & 0.30 & 0.49 & 7.8 & 0.76 & 0.22 \\
\hline 6 & 0.052 & 0.41 & 0.38 & 8.2 & 0.72 & 0.25 \\
\hline 7 & 0.055 & 0.32 & 0.42 & 7.3 & 0.77 & 0.28 \\
\hline 8 & 0.044 & 0.22 & 0.37 & 6.3 & 0.81 & 0.21 \\
\hline 9 & 0.045 & 0.20 & 0.28 & 6.0 & 0.84 & 0.22 \\
\hline
\end{tabular}


VIII INTERNATIONAL CONFERENCE «WELDING CONSUMABLES》

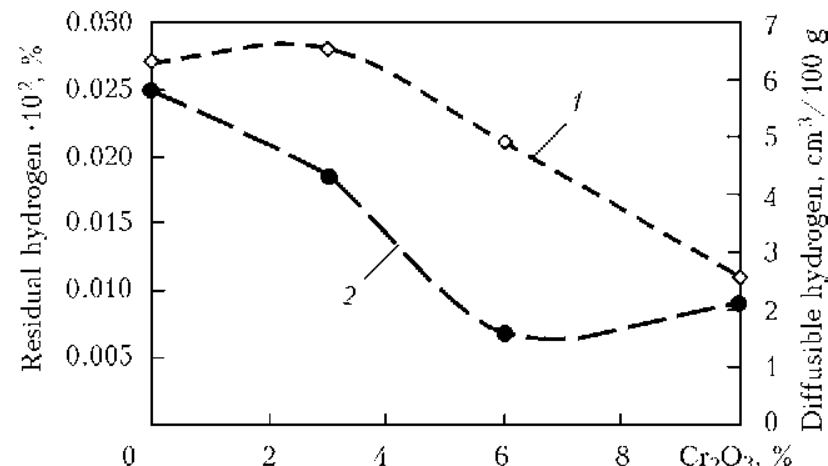

Figure 2. Effect of chromium oxide on content of residual (1) and diffusible (2) hydrogen in deposited metal $05 \mathrm{Kh} 6 \mathrm{MF}$

of carbon content in the deposited metal. This allows decreasing carbon content in the deposited metal to 0.04 wt.\% (Table 3).

Experiments on adjustment of coating composition were carried out for providing of optimum welding-technological properties. At that, effect of proportion of its components on quality of weld formation in different spatial positions, stability of arcing, easiness of slag crust separation and resistance of weld metal to pore formation were investigated. Evaluation of indices specified above was carried out on five-point grading system. Content of magnesite, fluorite and chromium oxide was changed in the ranges, wt.\%: 10-45 MgO, 10-45 $\mathrm{CaF}_{2}, 1-15 \mathrm{Cr}_{2} \mathrm{O}_{3}$ and 1-15 $\mathrm{ZrO}_{2}$. The experiments performed showed that proportion of magnesite and flourite has virtually no effect of arcing stability, but content of flourite above $35 \mathrm{wt} \%$ or chromium oxide more than 10 wt.\% promotes deterioration of weld formation in vertical position. Separability of slag crust becomes worse at reduction of chromium oxide less than 5 wt.\% and increase of magnesite more than $20 \mathrm{wt} . \%$. Optimum content of zirconium dioxide makes $2-6$ wt.\%.

Effect of coating composition on content of hydrogen in the deposited metal was also investigated. The experiments performed showed that introduction of chromium oxide is the most efficient for reduction of content of diffusible hydrogen at fired magnesite to flourite proportion 1.0:2.5. As can be seen from Figure 2, it is reduction of not only content of diffusible hydrogen, but content of residual one as well, that can be explained by bonding of hydrogen atoms into hydroxyl insoluble in liquid metal.
Thus, new flour-spar-magnesium-oxide slag system was proposed, providing carbon content in the deposited metal at the level of $0.04^{-}$ 0.06 wt. $\%$ and diffusible hydrogen at the level of $1.0 \mathrm{~cm}^{3} / 100 \mathrm{~g}$. Optimum content of coating was determined, and pilot batch of electrodes was manufactured. Test also showed significant improvement of welding-technological indices. Typical chemical composition of the deposited metal makes, wt.\%: $0.041 \mathrm{C}$; $0.23 \mathrm{Si} ; 0.47 \mathrm{Mn}$; $0.83 \mathrm{Mo} ; 0.25 \mathrm{~V} ; 0.017 \mathrm{~S} ; 0.026 \mathrm{P}$. Mechanical properties of the deposited metal in as-heattreated condition $\left(760{ }^{\circ} \mathrm{C}, 2 \mathrm{~h}\right)$ at $20^{\circ} \mathrm{C}$ characterized by such indices, namely $\sigma_{0.2}=290 \mathrm{MPa}$; $\sigma_{t}=515 \mathrm{MPa} ; \delta=30 \% ; \psi=65 \% ; K C U=$ $=62 \mathrm{~J} / \mathrm{cm}^{2}$.

Developed electrodes were marked as grade ANL-10 and specification on their production was prepared.

1. Skulsky, V.Yu., Tsaryuk, A.K. (2004) New heat-resistant steels for manufacture of weldments in heat power units (Review). The Paton Welding J., 4, 3237

2. Skulsky, V.Yu. (2005) Metal structure in the fusion zone and HAZ of welded joints on high-chromium heat-resistant steels. Ibid., 5, 10-18.

3. Erokhin, A.A. (1964) Kinetics of metallurgical processes of arc welding. Moscow: Mashinostroenie.

4. Erokhin, A.A., Kuznetsov, O.M. (1959) Electrodes with nonoxidation coating. Svarochn. Proizvodstvo, 12, 1-4.

5. Erokhin, A.A., Kuznetsov, O.M. (1961) Decrease in carbon content in weld metal during welding of stainless steels. Avtomatich. Svarka, 11, 1-4.

6. Sokolov, E.V., Sidlin, Z.A., Vagapov, I.M. (1968) Development of electrodes providing low carbon content in deposited metal of austenite class. In: Welding of structures from high-alloy steels. Leningrad: LDNTP.

7. Kakhovsky, N.I., Lipodaev, V.N. (1968) Electrodes for welding of chrome-nickel stainless steel of 18-10 type with low carbon content. Avtomatich. Svarka, 12, 8-10.

8. Kakhovsky, N.I., Lipodaev, V.N., Kakhovsky, Yu.N. (1970) Decrease in carbon content in weld metal during manual arc welding of stainless steels. Ibid., 6, $8-10$.

9. Knunyants, I.L. (1967) Concise chemical encyclopedia. Moscow: Sov. Entsycl.

10. Rode, T.V. (1962) Oxygen chromium compounds and chromium catalyzers. Moscow: AN SSSR.

11. Kakhovsky, N.I., Lipodaev, V.N., Zakharov, L.S. (1977) Decrease of carbon content in weld metal by high-temperature baking of electrode coating components. Avtomatich. Svarka, 2, 8-10.

12. Potapov, N.I. (1985) Oxidation of metals in fusion welding. Moscow: Mashinostroenie.

Received 04.04.2014 